\title{
Research Trainee
}

\section{Project George: An Indigenous Land-Based Approach to Resilience for Youth}

\section{Janice Cindy Gaudet}

\section{A R T I C L E I N F O}

Keywords:

Land-based learning

Indigenous resilience

Omushkego youth

Project George

https://doi.org/10.32799/ijih.v16i2.31668

\section{A UTHOR IN F O}

\begin{abstract}
A B S T R A C T
The research shared in this article seeks an understanding of Indigenous resilience within the context of a culturally responsive land-based initiative, Project George, led by the Moose Cree First Nation, also known as the Omushkego people. The initiative centres core Cree values, community engagement, and land-based skills to ensure the well-being of youth. Their Homeland is located in the waterways and on the western shores of the Hudson and James Bay Lowlands in Ontario, Canada. The methodology involved researcher participation and engagement as part of a 4-month field presence; informal conversations and visiting; as well as formal semistructured interviews with community members over 4 years from 2012 to 2015. The research explores the benefits and challenges of a land-based program by highlighting the experiences and voices of community and program participants who directly engaged with Project George. The findings show that land-based learning initiatives inspired and driven by Indigenous people foster a regenerative approach to wellness based on relation to land, culture, and identity. A return to land-based learning responds to the ongoing colonial complexities affecting the health and wellness of Indigenous youth in Canada and draws strength from the people's resilient practices.
\end{abstract}

Janice Cindy Gaudet, Assistant Professor, Canada Research Chair, Métis Relations and Land-Based Wellness, University of Alberta, Faculté Saint-Jean, Edmonton, Alberta, Canada. I am a proud Métis woman from a long lineage of Métis Matriarchs from Saskatchewan.Email: cgaudet@ualberta.ca 


\section{Acknowledgements}

Kinanaskomitin to the land and to the Moose Cree community for your generosity and for your tenacity in upholding beauty, resilience, and love.

\section{Introduction}

While there are various land-based initiatives in Indigenous territories and urban centres, learning in relation to the land and its Knowledge Holders is too often perceived from a Western viewpoint as noneducational, nonviable, or economically unsustainable, and is therefore not seen as worthy of long-term funding (Simpson \& Coulthard, 2014). By giving priority to Indigenous perspectives on resilience, colonial policies and attitudes rooted in deficit-based thinking about Indigenous people, can be confronted, and the value of land-based initiatives can be recognized within the context of Indigenous worldviews. Research is showing how land-based initiatives resist the colonial model by nurturing generations within a land-based approach (Gaudet, 2016; Simpson, 2014). This article draws on the emergent research on Indigenous resilience and its relationship to a particular land-based program, Project George, inspired and led by Moose Cree First Nation. The aim of this study was to better understand how Project George fosters resilience from within specific cultural, place-based, and land-based learning methods. The purpose of this study was to contextualize resilience from within mushkegowuk, meaning the things that belong to the Omushkego people, such as their lifeways, their land, their language, and their value system. Giving voice to a community's resilient practices, such as a land-based program for youth, Project George provides valuable insights into the relevance of communityled initiatives that support youth and community wellness.

\section{Place-Based Context}

The Moose Cree First Nation is situated on an island known as Moose Factory, Ontario, Canada - a homeland that has long served the diverse lives of Cree and Métis people, their families, and their land-centred lifestyles. The Moose River and James Bay area provided and continues to assure a sovereign and self-reliant Nationhood that is intimately connected to the land and to kinship ties, cultural knowledge, and relational laws and responsibility. The James Bay Treaty, understood as a Nation-to-Nation agreement, was signed in 1905. As with many such treaties in Canada, initial promises of prosperity and land access were abandoned, resulting in great loss and hardship for the people. As the Mushkegowuk Council (mushkegowuk.ca) confirms and Long's (2010) research supports, the King's promises to the people about their ability to harvest their traditional foods and to be protected from living on the reserve were broken amid such false claims as "The King wants you to be prosperous and happy" (Long, 2011). These broken promises are all too familiar to Indigenous Peoples in Canada, and the resulting losses have had a devastating intergenerational impact on people's connection to the land, access to food sources, the well-being of families, kinship systems, and Omushkego identity. The profound disruption of colonial policies, including Indian residential schools, and control of access to food, has had long-lasting effects on Indigenous people's lives. These effects 
include addiction, psychological and spiritual distress, chronic conditions, and a negative impact on social learning and parenting (Bombay et al., 2011; 2014; Brave Heart, 2003; WesleyEsquimaux \& Smolewski, 2004; Wesley-Esquimaux 2009). Research has well demonstrated the complexity of colonial trauma specifically linked to residential schools (Truth and Reconciliation Commission of Canada, 2015). One of these effects is that many families did not have the opportunity to live with and learn from the land due to the gap in knowledge sharing and transmission from generation to generation. The Moose Factory community's awareness of the intergenerational effects of residential schools has led to their creating their own solutions that address the importance of reconnecting to the land. Project George is one of the many efforts providing alternative processes and resilient practices that reflect the criticality of reconnecting youth to their land, to mushkegowuk, as key to their wellness.

\section{Project George}

This land-based program began in 2009, when Charlie Cheechoo, who would go on to become the project coordinator, received a simple request from an Elder and a youth to take them out fishing. This request, which he took seriously, eventually led to his organizing Project George in partnership with a local land-based camp owner. Although a fishing trip initially seemed like a simple intervention in response to the significant challenges the youth were facing, the initiative grew to become more formalized, and eventually would increase in demand from informal fishing trips to 10 organized trips per year with an average of 10 to 15 youth per excursion. Project George supports their youth to experience being out on the land, and to reconnect with Cree traditions with an aim to grow personally and to heal from the impacts of colonialism.

In 2009 and for several years, Project George operated with support from the band council and donations from local organizations and corporations. Community fundraising also played a significant part in the project's success. The resources acquired helped to pay for camping equipment, camp rental, travel costs, equipment repairs, food, and basic salaries for the coordinator and helpers. As Project George expanded, becoming coed and increasing its activities, it also received more external funding and collaborated more effectively with community partners and eventually sparse pockets of short-term government funding. Charlie's 30 years of experience with Cree youth in various capacities has fostered deep compassion and understanding of the struggles they face with drugs, alcohol, poverty, low school attendance, intergenerational trauma, and family breakdown. With the growing number of suicides in 2010 (Mushkegowuk Inquiry Into Our Suicide Pandemic, 2014), Charlie was driven to reconnect youth to the land, and to reach out to youth in the community who are isolated from formalized community programming. Guided by increasing requests from the youth, his motivation was met with financial and moral support from the community. The initiative quickly became respected as a needed approach that supported the well-being of youth by exposing them to Cree skills, knowledge, and values that are unique to place and people.

Project George's methodology involves taking adolescents out on the land, where they learn by doing, observing, and teaching Cree land-based skills such as fishing, trapping, hunting, 
setting up camp, firearms use, water navigation, food preparation, bush work ethics, community service, and visiting with one another. The program proudly promotes unstructured activities, enjoyment, and leisure. Although working with at-risk youth demands seriousness, rigorous leadership, and persistence on Charlie's part, humour prevails at Project George. Many in the community respect his overall approach to championing youth well-being.

Unlike an orientation program that simply provides youth with a one-time experience, the goal is for participants to return for multiple excursions, and over time, to grow a community of leadership based on learning from and on the land. Smaller groups of young men participate in spring and fall hunts out on the land for up to a month. These hunting trips are in addition to the programming requested from local institutions, such as churches and schools. In 2015, Project George started to work with youth from Moosonee, a community across the Moose River. The local police also collaborate in the project's management by communicating with the Project George coordinator on a regular basis and by referring youth to take part in community service and land-based excursions as part of community-led initiatives. The aim is to respond to "unlawful conduct" with a culturally based approach led by the community, given the community best knows its history, its people, its needs, and its well-being solutions.

The timing of excursions varies according to seasonal changes and ecological rhythms, offering a flexible yet stable structure that teaches youth to live in relationship with the land. The land-based activities are structured in accordance with the environment, the movements of animals, weather patterns, seasonal cycles, and the needs of the community. For example, young people are not taken out during bug season in July, nor the season of the freeze-up in November and December. August programming is organized in conjunction with community organizations because the young participants are out of school. During the months of September and October, the focus is on hunting moose, setting nets, and gathering wood for the winter. January through March is a time for trapping, winter camping, cutting wood, and hunting. The knowledge and skills taught through Project George include setting up hunting blinds (a cover for hunters) and building tent frames and lean-tos. There is an important element of training: those who carry the knowledge teach those who did not grow up with this knowledge. Through this process, the youth learn, for example, tracking rabbits and setting snares, catching and cleaning fish, and hunting and gutting moose.

The research participants often spoke of the importance of helping other young people, and families, who would not otherwise have the opportunity to go out on the land because of circumstances beyond their control. "It is a great thing what he [Charlie] is doing. To teach them what the parents can't and to provide the experience. It's pretty big" (Project George youth helper, January 14, 2014). Along with other roles and responsibilities, participants in Project George learn the importance of caring for the community, for example: bringing firewood to Elders, sharing the food harvest with Elders and at community gatherings, assisting in community events, welcoming visitors, and sharing their learned skills and knowledge with other youth. These skills and knowledge include training in first aid, chainsaw and firearms safety, safe driving on snow and ice, and Moose Cree safety and survival skills. Courses are adapted in 
accordance with weather conditions, the changing environment, participants' skill levels, and emergent needs, in order to effectively cater to the growing number of Project George participants.

\section{Toward Understanding Indigenous Resilience}

Research on resilience has focused on the ability to positively adapt despite adversity and hostile conditions (Luthar et al., 2000). While this understanding of resilience in relation to Indigenous Peoples may be relevant within the fields of psychology, psychopathology, and psychiatry, new research has begun to explore resilience using Indigenous ontology, epistemology, and methodology. This reframing of resilience is most often grounded in relationships to the land, family, community, place, history, language, and identity (Allen et al., 2014; Brendtro et al., 2009, 2013; Isbister-Bear et al., 2017; Kirmayer et al., McGuire, 2010; 2011; Simpson, 2014; Simpson \& Coulthard, 2014). The research by Kirmayer et al. (2011), framed in reference to "mental health promotion, policy and clinical practice" (p. 84), highlights the importance of rethinking resilience from Indigenous perspectives. Their findings show that the sources of resilience are distinct among different Indigenous groups, and include relation to land; Indigenous concepts of treaty relations; stories of Creation, culture, and language; distinctiveness; resourcefulness; and worldview. The distinctiveness of Indigenous resilience is often shown by descriptions that include the term land-based, used increasingly to describe "the inseparability of land and water from our health and wellbeing" (Redvers, 2016, p. 1).

Brokenleg's (2012) resilience work helps to contextualize the Indigenous worldview of resilience, given that connection to the land and well-being are embedded in Indigenous knowledge systems. His research speaks to the recognition of human dignity and belonging as a way to address the deeper issues involved in intergenerational trauma that result from oppressive colonial policies, attitudes, and systems. Brokenleg (2012) explains that the "worst kind of oppression is internalized. Once it is in someone's head, it's hard to remove" (p. 11). Brokenleg's philosophical and practical approach of reclaiming youth is also evidenced in Project George (Brokenleg \& Van Bockern 2003). The project's land-based approach supports the youth, and their families generate meaning from their worldview and experience. As McGuire (2010) argues, reframing resilience from an Indigenous context offers a meaning that emphasizes Indigenous people's success stories.

In my discussions about resilience with an Omushkego Knowledge Keeper, he explained that mushkawiseeo (meaning mental and physical strength of character) is a built-in safety mechanism that protects children. It comes from the Creator. Another Moose Cree language speaker and Knowledge Keeper confirmed that when describing resilience in relation to Project George, the relevant word would be mushkowahtisiwin, meaning strength. My limitations as a non-Cree-speaker made it difficult to unpack the deeper meaning embedded in the language, but at the same time, I am learning how Indigenous languages intersect with ways of being, doing, and thinking in relation to what it means to live and to be well. As a Métis community-engaged scholar from Saskatchewan and part of a strong lineage of Métis women, I recognize my position 
as a visitor on Treaty 9 territory and my relational accountability to the participants and their families, as well as my responsibility to return home to learn of my own history, language, resilience, and stories of my own relatives.

Resilience that comes through the land involves perceiving the land as teacher and healer (Radu et al., 2014; Simpson, 2014). There is also a social aspect worthy of being highlighted. To conceptualize the land as a tenet of resilience, the land-based programming of the Cree Nation of Chisasibi shows how social and familial relations start to mend and heal through their respective life teachings (Radu et al., 2014). The process of learning from and with the land is entwined with the values of respect, reciprocity, and responsibility in relation to the cosmology of the land, as demonstrated also in Moose Cree's Milo Pimatisiwin Project (Gaudet \& Chilton, 2018). This process rejects a settler-colonial approach to learning that separates the learner from their environment, further distancing the learner from the meaning of a "balanced relationship of mutuality" (Simpson, 2014, p. 12). Given that settler-colonialism seeks to erase Indigenous Peoples through land acquisition and control, land-based wellness entails a conscious departure from Western compartmentalized notions of health, well-being, and education. Learning comes from the land and is guided by "the social relations, knowledges and languages that arise from the land" (Wildcat et al., 2014, p. I). Regenerating Indigenous methods of learning from and with the land centres Indigenous perspectives and cultural identifiers regarding what it means to sustain the deeper meaning of life, as expressed in the Moose Cree language-pimatisiwin. In this way, land-based initiatives are a form of resisting colonial dominance by shifting cultural identity such that the land is guiding how to be in good relationships, which as many Knowledge Keepers expressed include land, plants, trees, stars, and animals.

\section{Research Framework}

This work is part of a university and community research partnership that began with a pilot project developed by an international sport-for-development nongovernmental organization in 2010. The pilot project aimed to bring Western-based life skills and youth leadership training into First Nations communities. As part of my doctoral studies, I was invited to refocus my research to highlight the value of land-based initiatives for youth, inspired and led by the Moose Cree First Nation people themselves. In addition to University of Ottawa research ethics approval, an official letter of invitation was provided by the band council as part of their community engagement. Participants who agreed to have their names in the article were honoured in this way, and those who chose not to were respected accordingly. Visiting informed many of my conversations; these exchanges occurred during various daily activities, such as harvesting, food preparation, ceremonies, social gatherings, driving around, meals, and tea. The visiting way was (and remains) central to maintaining connection to Métis and Cree kinship relations and taking care of each other and the land through our relational responsibilities and accountability (Gaudet, 2019). Some exchanges included semistructured interviews that focused on Project George, its purpose, project logistics, the participants and their struggles, the results, strategies, and challenges related to continuity of a culturally specific initiative.

V OLUME 16 , IS S UE 2, $2021 \bullet 182$ 
This research presents data based on conversations and on 13 semistructured interviews ( $n=4$ female adults, 6 male adults, 3 young male adults) with individuals directly involved with Project George, in addition to Cree language speakers. More specifically, the 13 participants included four elected members of the band council, the coordinator of Project George, three Project George workers, three community Elders, a school principal, and a camp owner. Given I participated in a Project George weekend camp, some of the interviews took place during the camp with those directly involved in program delivery, leadership, and administration. The young male adults were invited to share their experiences given their involvement first as youth in the program and later on as employed helpers. I spent a total of 4 months in the community over a 4-year period from 2012 to 2015, with my main working location being at the community youth centre, where the Project George office was located. Given that community's longstanding commitment to their young people's wellness, it was important to draw on numerous conversations that provided insight into how Project George's reconnecting of youth to the land could be a source of resilience and of community strength. People were often willing to share spontaneously their views on Project George when they learned that my research focused on this community project.

\section{Methods and Data Analysis}

The methods were participatory, experiential, and conversational, through visiting as well as semistructured interviews. The community members engaged in working with Project George wanted to give meaning to their own program and their role within it. I interviewed two helpers together per their request and then we continued the conversation over a meal and the excursions on the land. Another youth offered his perspective over the phone as we were not able to meet in person. When it became known that Project George was the focus of research, community members offered their input during our visiting times, given the community's commitment to youth wellness and their recognition of the role of the land. The elected band council who were available to meet were invited to participate, given they were invested in giving a voice to their community-led and community-funded initiative. These interviews lasted from 45 minutes to an hour. I would often share with community members that became friends what I was learning and ask what I was missing in my understanding. In doing so, they would help interpret the findings. We would have a dialogue exploring the multilayered significance, complexities, and impact of Project George.

As part of requesting written consent where possible and oral when necessary (especially when out on the land), participants were explained the university ethics process, our shared responsibility to conduct ethical research, and their right to withdraw. I was invited to attend family and community events, forums, and Project George camp itself. A recurring invitation was for me to actually participate in the program if I were to understand the model and its impact. My field notes and interview recordings and notes were transcribed and coded in NVivo 10 using a thematic analysis to identify recurring themes on the role of the land and the benefits and challenges of the program. The findings were reviewed and discussed with two research participants and one community member to ensure accuracy, as well as with two language 
keepers as part of the process of situating worldview embedded in their language. The findings reflect what the research participants said, community forums, and strategic planning documents. In addition, they reflect profile-raising community-crafted materials on the importance of reconnecting youth to the land that were shared with me.

\section{Findings}

The findings demonstrate the ways in which Project George protects and reignites landbased wellness. By reclaiming land as a site of learning, teaching, and sharing knowledge, the youth draw strength from their own experience and from contact with place and people. Belonging to the courageous spirit of mushkegowuk is best strengthened from within the place, the stories, and the paths of their ancestors. The following themes emerged from the conversations and interviews.

\section{Land as Healer}

Intergenerational stressors are a burden that plagues the well-being of youth and their families. These stressors are seen as a result of the devastations of residential schools and the way they shattered people's connection to land, language, family, and spirituality. Project George was seen as a way to provide guidance and direction in dealing with these intergenerational stresses. "The young ones are the ones out there struggling and are confusedwe need to help them, guide them, and show that we care for them" (Participant, January 15, 2014). The land as helper and healer encourages both self-reliance and alertness. "Things are going to happen to the land and you have no control over what's going on. You're just going to have to get your wood, get ready, eat, take care of yourself, stay warm" (Participant, January 15, 2014). Those who have lived on the land and known it intimately often refer to equanimity as a form of clear thinking required to survive on the land. Many of them learned the skills of vigilance toward their environment from their grandparents, uncles, and aunties. These qualities, taught with firmness but also kindness, are fostered and perceived as vital in order to survive and to respond to the precarious ecosystem.

Two of the young people working for Project George at the time of this research shared how going out on the land helped them "keep their minds off things, keeps me rested, and relaxed." When out on the land, a relaxed and unburdened mental state lessened their desire to use substances.

I don't even think about drugs and alcohol when I'm out there. You just do what you do. Fish. Relax and work. When I am out on the land, I am at peace. I go there every chance I get, and I stay as long as I can. (Participant, January 14, 2014)

Moose Cree First Nation created a short film footage highlighting Project George (available in DVD form). This included a conversation with a community youth, Allan Gagnon, who shared both his vulnerability and his motivation to bring youth back to the land. $\mathrm{He}$ 
explained how his thoughts of suicide subsided after he started working with Project George. He later went back to college, then returned to Moose Factory to work full-time for Project George, doing what he loves - taking young people out on the land.

The youth explained to me how they shifted from feeling that they were carrying the weight of everyday community and family burdens to an active lifestyle. When discussing the land at the heart of the work, they often described this in the context of an increased sense of value, a mental state of peacefulness, and the development of skills for navigating the complexities of the bush landscape, waterways, tides, and the changing movements of polar bears. Though Project George provides the technical bush skills of food preparation, safe use of firearms, hunting and tracking animals, and setting up snares, it also teaches participants how to read and know the environment, such as finding one's way when lost, locating navigation points, identifying landmarks, communicating effectively, observing acutely, and looking out for and helping one another as needed. Some participants felt that with repetition of these activities, the ability to teach to the younger ones came automatically. Teaching was seen as a form of caring for one another. An awareness of the increase in physical activity when out on the land was perceived as following the ancestors' ways of life.

\section{Land as Teacher}

Project George provides a setting to learn outside of the island boundaries. Out on the land, participants felt they interacted differently with one another than in the community. They emphasized how the land changes a person - changes one's perception and the ways one relates to oneself and others. The focus was not on the length of time in which this change occurs, but rather how important it is "to get out there. The more you go, the more the change stays with you" (Participant, January 17, 2014). "When we are stuck on the island, it makes us feel screwed up and confused. We feel best on the land. It's home" (Participant, January 15, 2014). There was an increased awareness of the difference between individualistic attitudes and holistic community-based caring and sharing practices as a way of living well.

When one is out on the land, another way of being and relating takes root. Participants frequently emphasized that out on the land, everyone knows what to do; behaviour changes, the atmosphere is more relaxed, and the way of communicating even changes. There is a change in perception that was explained through teaching stories. One particular repeated story refers to an old man who spent much of his life in the bush: "In his mind, everything that is feeding usCreator, moose, animals, water - they are helping us. You need knowledge to think this way" (Participant, January 15, 2014). Project George expands thinking on Indigenous resilience to include particular themes - belonging to the land, belonging to a people, having a purpose, preparing oneself and one's family to be out on the land - and offers a set of values that young people can draw strength from. "If there wasn't a lesson to be taught as I was learning, there would be a story to be told to inspire us to keep our traditional living alive and well throughout our families and communities" (Participant, August 6, 2014).

Participants saw the bush skills they learned as essential for fostering a relational way of being, and a respect for how life was in the past. The skills, methods, and ethics learned were

V OLUME 16 , IS S UE 2, $2021 \bullet 185$ 
seen as helpful for thinking critically about everyday modern conveniences and processed foods. Many research participants saw reconnecting to the land as significant in helping them to move away from reliance on government, and to once again return to self-reliance and reliance on land-based foods and one another.

According to the research participants, motivation for young people to go back to the land was not based on the badge-reward systems of Western programs such as the Boy Scouts. Rather, as one participant stated, "First Nations people, we don't get badges for what we do. We just do this because we have to" (January 17, 2014). The young people feel proud of what they have learned, and of their ability to teach others who never grew up on the land. "The experience comes from within themselves. It is because they want to learn" (Participant, March 19, 2014). This idea of motivation from within is echoed by the young people themselves. "Training with Project George actually made me confident, comfortable, and also gain new knowledge of the outdoors than I have recently possessed within myself" (Participant, March 2015).

The youth who worked with Project George as helpers were enthusiastic about "learning new things" (Project George youth helper, January 14, 2014). They expressed a sense of accomplishment, not only for their personal achievements, but also for their increased capacity to help, and to know, their own people. "It shows where our people come from, being out thereour tradition and our culture" (Participant, January 14, 2014). Being of service to one another in order to improve community and family life was a recurring theme among the research participants. They recognized the aspect of service embedded in Project George. For example, they serve family and community by bringing Elders wood and land-based foods after hunting trips. For the project coordinator, "Cree values are about sharing, being kind to one another, and helping each other out" (January 13, 2014). Project George was seen as reasserting these values, and promoting a "do it ourselves" attitude. Some participants felt that Project George awakened a desire for adults to learn. I experienced this myself when I participated in the community's land-based initiatives. Project George offers new avenues for learning, and a return to mushkegowuk ways, for all generations.

\section{"Going Back to the Land"}

"Going back to the land" was a recurring theme. Going back is taking back what was lost in an imposed welfare life that took away people's self-reliance and pride in a strong work ethic and identity. To return was to reclaim land-based practices, Cree values, dignity, pride in being Cree, and a lifestyle of actively and creatively working with the land. Project George provides an opportunity for youth and community together to "take back" their lives by taking responsibility for the process of recovering from their losses and being of service to the community. This return was also expressed as a method of taking care of future generations.

The act of "going back to the land" elicited within the community a critical look into the future, a realization that they must direct their actions toward supporting the younger generation. This critical look also involved a look back, a look into the present circumstances affecting young people's well-being, and a commitment to land-centred initiatives based in the people's 
own Cree intelligence. "They will need to go back to the land to live off the land. One day, they will need to learn off the land again. For some this is a hobby, but for us it is a way of life" (Participant, March 19, 2014). There was an emphasis on preparing young people to respond to the unknowns of the world, to develop skills for self-reliance, and to be calmly responsive to their environment.

For the community, this idea of "going back" involves an acknowledgement that some community members still have knowledge of the land, but also a deep sensitivity to the fact that some never had this opportunity, for various reasons - one often discussed is the Indian residential school system. Although community members are aware that recovering from their loss will take time, there is also a sense of urgency to learn from those who have bush skills and knowledge of the land. One of the participants felt that perhaps the community had failed to address certain deeply rooted issues in the 1970s, 1980s, and 1990s, yet there is new hope that some of these issues are being addressed through Project George. For many in the community, Project George addresses what has been missing — what went wrong in the past. The spark of motivation for band and community engagement was expressed as follows:

I know we are going to depend on the youth shortly. They are going to be the leaders. ... But at the same time, before we do that, they need to take a lot of the knowledge required from the Elders, from their parents. They still need to be nurtured. (Participant, January 17, 2014)

\section{Nurturing Mushkegowuk}

Having a dedicated coordinator and helpers is essential to the sustainability of Project George. It takes a significant effort to uphold the aims of land-based learning. The program emphasizes the importance of being able to practise what is learned. The transfer of knowledge and skills is not only between generations, but between family members, something that comes naturally in a culture where learning occurs through observation and by doing. Indeed, those who went out on the land as children have carried their knowledge into their adult lives. The research participants expressed that Project George helped them to remember their roles and responsibilities in relation to community and family well-being. They also felt that land-based initiatives reestablish a holistic approach involving learning from one another, valuing difference, and working together to pass on inherent rights and Cree knowledge. What is valued is not "perfection," but rather humility, connectivity, relationships, presence, and enjoyment.

There is a way of doing things. It is not about being perfect, it is about being mindful of the moments - having fun doing things. Learning through fun is how we hold things more to our heart. It is making a connection to grandfather, grandmother, uncles. ... It is your relations that contribute today. (Participant, January 15, 2014)

For the community members, it was significant that Project George engages youth by welcoming them for who they are, accepting them for where they are in their life journey, and offering respectful guidance through experiential learning-by-doing methods. According to 
Charlie Cheechoo and others, this is a key element of its ongoing interest. Charlie expressed the importance of 3 things: considering the opinions of the young people, selecting Elders that value and respect their life stage journey as young people, and having a sense of humour. The young people are able to express themselves honestly without fear of reprisal. They are consulted throughout the process, and play an active role in decision-making. As the land-based camp owner explained, when out at the camp, no one is forced to go out into the bush. It is clear that in creating the right environment for youth, various factors have been taken into careful consideration.

Unlike the more structured "life skills" training typical in an urban context, Project George is relaxed and fluid. One of the participants expressed what many community members seem to notice when going out on the land. He observed the ways in which the young people related to one another on the second day of being at the camp:

A natural bonding occurs just letting youth visit, share, and be together. Their days are not filled with keeping them active and entertained. We like to keep it simple. ... We are here to learn the land and from the land. (Participant, March 19, 2014)

In this model, young people are respected as knowers and natural seekers. "Young people know there is something there, just need to get them out. Then they can choose to go to Cuba or to the bush" (Participant, March 19, 2014). The governance of Project George, informed by respect to the land, to the young learners, and to community, points to a web of resilience that is "built in," as Omushkego Elder William Louttit describes in the best way he could translate from a language that does not have such a term.

\section{Discussion}

The research findings show that Project George plays a vital role in guiding young people, families, and the community toward reconnection to land-centred cultural identity. It is, in fact, the land that makes one resilient, and it is connection that makes the land resilient. This interaction with the land is paradoxical but also dialogical, and mutually beneficial given that the land also needs our connection to be well. Pimatisiwin - life - is given value through learning new skills, interacting with and living in relation to the land, visiting with others, and sharing knowledge with other members of the community. Optimistic reflections from the community demonstrate the potential for initiatives that reconnect people to the land, to their ancestors, and to Cree culture as way of supporting the betterment of young people's lives. Project George supports the learning of a way of life that values responsibility, relational accountability, and taking care of the community. Beyond merely boosting participants' self-esteem, it instills a sense of belonging, cultural pride, and feeling "better about themselves and their abilities" (Charlie Cheechoo, quoted by CBC News, 2012). It emphasizes the importance of having funenjoyment - while also staying safe while being on the land. Leadership of the program is vital to its continuity, as is community engagement. 
Grounded in Cree values, kinship, methods, and lifeways, Project George plays a vital role in asserting cultural identity. It reflects a form of resurgence that regenerates individual and collective spirit in relation to the land. Given this, it is critical that land-based initiatives are not examined through a Western lens of viability, success, and sustainability, as this risks dismissing Indigenous knowledge and creating ongoing barriers to access adequate resources. Rather, they need to be examined from a social, cultural, spiritual, and historical context. Also risky are attempts to adapt Western-based programs to fit Indigenous cultural knowledge in an effort to insert themselves into an Indigenous worldview. Such an approach downplays the value of Indigenous ways of thinking, doing, and being, and suggests that the challenges are merely Indigenous. As long as Western-based models for youth programs are perceived as more legitimate, the land is disregarded as the source of resilience and the source of life. Indigenousled programs, preferably on our lands, connect youth to their identity, community mentors, land, waters, cultural stories, traditional knowledge, and language.

\section{Conclusion}

Indigenous resilience is complex, given that it is linked to colonial disruptions and legacies of assimilation. Yet, as explained by Moose Cree Knowledge Keeper William Louttit, "it [resilience] is built inside of us. Creator made us that way so that we don't have to always be carrying the burdens of the past" (March 17, 2017). With land as the very core of Indigenous people's worldview and the core of the colonial conquest, there is a critical urgency of re-rooting new generations of young people in land-based knowledge. Project George is a celebration of community strength as we take up our kinship responsibilities to uplift generations of young learners as a part of milo pimatisiwin, meaning living and being well.

\section{References}

Allen, J., Hopper, K., Wexler, L., Kral, M., Rasmus, S., \& Nystad, K. (2014). Mapping resilience pathways of Indigenous youth in five circumpolar communities. Transcultural Psychiatry, 51(5), 601-631. https://doi.org/10.1177\%2F1363461513497232

Bombay, A., Matheson, K., \& Anisman, H. (2011). The impact of stressors on second generation Indian residential school survivors. Transcultural Psychiatry, 48(4), 367-391. https://doi.org/10.1177\%2F1363461511410240

Bombay, A., Matheson, K., \& Anisman, H. (2014). The intergenerational effects of Indian residential schools: Implications for the context of historical trauma. Transcultural Psychiatry, 51(3), 320-338. https://doi.org/10.1177\%2F1363461513503380

Brave Heart, M. Y. H. (2003). The historical trauma response among Natives and its relationship with substance abuse: A Lakota illustration. Journal of Psychoactive Drugs, 35(1), 7-13. https://doi.org/10.1080/02791072.2003.10399988

Brendtro, L. K., Brokenleg, M., \& Van Bockern, S. (2009). Reclaiming youth at risk: Our hope for the future. Solution Tree. 
Brendtro, L. K., Brokenleg, M., \& Van Bockern, S. (2013). The circle of courage: Developing resilience and capacity in youth. International Journal for Talent Development and Creativity, 1(1), 67-74. http://www.ijtdc.net/index.php/e-copies/ijtdc-1-1-2013

Brokenleg, M. (2012). Transforming cultural trauma into resilience. Reclaiming Children and Youth, 21(3), 9-14.

Brokenleg, M., \& Van Bockern, S. (2003). The science of raising courageous kids. Reclaiming Children and Youth, 12(1), 22-27.

CBC News. (2012, June 12). Kids are getting wrong message about suicide. https://www.cbc.ca/news/canada/sudbury/kids-are-getting-wrong-message-about-suicide1.1177353

Gaudet, Janice Cindy (2016). An Indigenous Methodology for Coming to Know Milo Pimatisiwin as Land-Based Initiatives for Indigenous Youth. Doctoral dissertation, University of Ottawa.

Gaudet, J. C. (2019). Keeoukaywin: The visiting way-Fostering an Indigenous research methodology. Aboriginal Policy Studies, 7(2), 47-64. https://doi.org/10.5663/aps.v7i2.29336

Gaudet, J. C., \& Chilton, C. (2018). Milo Pimatisiwin Project: Healthy living for Mushkegowuk youth. International Journal of Indigenous Health, 13(1), 20-40. https://doi.org/10.32799/ijih.v13i1.30264

Isbister-Bear, O., Hatala, A. R., \& Sjoblom, E. (2017). Strengthening Âhkamêyimo among Indigenous youth: The social determinants of health, justice, and resilience in Canada's north. Journal of Indigenous Wellbeing: Te Mauri - Pimatisiwin, 2(3), 76-89. https://journalindigenouswellbeing.com/media/2018/07/59.91.StrengtheningÂhkamêyimo-among-Indigenous-youth-The-social-determinants-of-health-justice-andresilience-in-Canada's-north.pdf

Kirmayer, L. J., Dandeneau, S., Marshall, E., Phillips, M. K., \& Williamson, K. J. (2011). Rethinking resilience from Indigenous perspectives. The Canadian Journal of Psychiatry, 56(2), 84-91. https://doi.org/10.1177\%2F070674371105600203

Long, J. S. (2010). Treaty No. 9: Making the agreement to share the land in far Northern Ontario in 1905. McGill-Queen's University Press.

Long, J. S. (2011, January 17). Q\&A with John S. Long, author of Treaty No. 9 [Interview]. McGill-Queen's University Press. https://www.mqup.ca/blog/qa-with-john-s-longauthor-of-treaty-no-9/

Luthar, S. S., Cicchetti, D., \& Becker, B. (2000). The construct of resilience: A critical evaluation and guidelines for future work. Child Development, 71(3), 543-562. https://doi.org/10.1111/1467-8624.00164

McGuire, P. D. (2010). Exploring resilience and Indigenous ways of knowing. Pimatisiwin: A Journal of Aboriginal and Indigenous Community Health, 8(2), 117-131. http://www.pimatisiwin.com/online/?page_id=780

Moose Cree First Nation (Producer). (2014). Project George: Reconnecting with the land [Video]. Accessible on DVD from Moose Cree First Nation Band office 
Mushkegowuk Inquiry Into Our Suicide Pandemic. (2014). Nobody wants to die-They want the pain to stop. The People's Inquiry Into Our Suicide Pandemic: Final Report. http://www.mushkegowuk.com/documents/dec2014_peoplesinquiryreport.pdf

Radu, I., House L. M., \& Pashagumskum, E. (2014). Land, life and knowledge in Chisasibi: Intergenerational healing in the bush. Decolonization: Indigeneity, Education \& Society, 3(3), 86-105. https://jps.library.utoronto.ca/index.php/des/article/view/21219

Redvers, J. (2016). Study: Land-based practice for Indigenous health and wellness in the Northwest Territories, Yukon, and Nunavut. Plain Language Research Summary and Recommendations. http://www.ichr.ca/wp-content/uploads/2016/11/Land-basedResearch-Summary_2016.pdf

Simpson, L. B. (2014). Land as pedagogy: Nishnaabeg intelligence and rebellious transformation. Decolonization: Indigeneity, Education \& Society, 3(3), 1-25. https://jps.library.utoronto.ca/index.php/des/article/view/22170

Simpson, L., \& Coulthard, G. (2014, November 26). Leanne Simpson and Glen Coulthard on Dechinta Bush University, Indigenous land-based education and embodied resurgence [Interview]. Decolonization: Indigeneity, Education \& Society. https://decolonization.wordpress.com/2014/11/26/leanne-simpson-and-glen-coulthard-ondechinta-bush-university-indigenous-land-based-education-and-embodied-resurgence/

Truth and Reconciliation Commission of Canada. (2015). Honouring the truth, reconciling for the future: Summary of the final report of the Truth and Reconciliation Commission of Canada. http://www.trc.ca/assets/pdf/Honouring_the_Truth_Reconciling_for_the_Future_July_23 _2015.pdf

Wesley-Esquimaux, C. C. (2009). Trauma to resilience: Notes on decolonization. In G. G. Valaskakis, M. D. Stout, \& E. Guimond (Eds.), Restoring the balance: First Nations women, community, and culture (pp. 13-34). University of Manitoba Press.

Wesley-Esquimaux, C. C., \& Smolewski, M. (2004). Historic trauma and Aboriginal healing. Aboriginal Healing Foundation. http://www.ahf.ca/downloads/historic-trauma.pdf

Wildcat, M., McDonald, M., Irlbacher-Fox, S., \& Coulthard, G. (2014). Learning from the land: Indigenous land-based pedagogy and decolonization. Decolonization: Indigeneity, Education \& Society, 3(3), I-XV. https://jps.library.utoronto.ca/index.php/des/article/view/22248 